\title{
INTERACCIÓN CREADORA ENTRE TEXTO E IMAGEN EN EL MICRORRELATO FANTÁSTICO PENINSULAR EN LAS PRIMERAS DOS DÉCADAS DEL SIGLO XXI
}

\author{
Marta Simó-COMAS \\ University of Reading \\ marta_simo@yahoo.es
}

Recibido: 18-07-2021

Aceptado: 13-12-2021

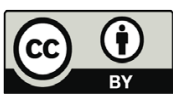

RESUMEN

En la coordenada temporal de las dos primeras décadas del siglo XXI y centrándonos en el microrrelato fantástico, el presente estudio tiene como objeto explorar la interacción creadora que microrrelato e imagen establecen en el contexto de lo insólito. Para ello, y tomando como referencia metodológica la noción de intermedialidad, analizaremos cuatro combinaciones mediales en las que texto e imagen se determinan recíprocamente: Cuentos malvados (2010), de Espido Freire, Cuentos del libro de la noche (2005), de José María Merino, Formulaciones tautológicas (2010), de Felipe Benítez Reyes (2010), y Casa de muñecas (2012), de Patricia Esteban Erlés. Asimismo, consideraremos Ajuar funerario. El cómic: Difuntos, infantes y monstruos (2018), de Imanol Ortiz y Beñat Olea para ilustrar los mecanismos de la transposición medial.

Palabras Clave: Intermedialidad; texto e imagen; microrrelato fantástico; adaptación; narrativa siglo XXI. FANTASTIC MICROFICTIONS IN THE FIRST TWO DECADES OF THE 21st CENTURY

\section{ABSTRACT}

Framed within the first two decades of the 21st century and focusing on the micro-story of the fantastic, the present study aims to explore the creative interactions esta- 
blished between micro-story and image in the wider realm of the uncanny. For this purpose, and taking as a methodological benchmark the concept of intermediality, we will analyse four media compositions in which meaning is determined reciprocally by text and image: Cuentos malvados (Wicked Tales) (2010) by Espido Freire, Cuentos del libro de la noche (Tales from the Book of the Night) (2005) by José María Merino, Formulaciones tautológicas (Tautological Formulations) (2010) by Felipe Benítez Reyes and Casa de muñecas (Doll's House) (2012) by Patricia Esteban Erlés. We will also consider Ajuar funerario. El cómic: Difuntos, infantes y monstruos (Funerary trousseau. The Comic: Dead People, Infants and Monsters) (2018), by Imanol Ortiz and Beñat Olea, to illustrate the mechanisms of medial transposition.

KEYWORDS: Intermediality; text and image; micro-stories of the fantastic; adaptation; $21^{\text {st }}$ century narratives.

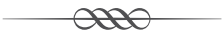

\section{INTRODUCCIÓN}

Cuando un día de principios de los sesenta Jaime Buesa, joven colaborador de La Vanguardia, se acercó a Esther Tusquets con un proyecto innovador en el que se combinaban fotos de chiquillos de barrios marginales de Barcelona con unos relatos breves de Ana María Matute en la línea de Los niños tontos (1956), la editora supo inmediatamente que estaba ante algo extraordinario. El libro se llamó Libro de juegos para los niños de los otros (1961) y supuso el inicio de una de las colecciones más celebradas de Lumen: Palabra e Imagen (Tusquets; 2012: 42).

Con esta serie, pionera en el uso integrado de fotografía y literatura, se abría en España un campo de posibilidades que a lo largo de los años ha ido fraguando en múltiples variaciones de este formato, consistente en fusionar los códigos lingüístico e icónico para formar un único mensaje, complejo e integrador. Collages, dibujos esquemáticos o elaboradas ilustraciones son algunas de las modalidades visuales que se ensamblan con el texto en un mismo espacio de comunicación, y de todas ellas nos ocuparemos en el presente trabajo. Sin embargo, es fundamental acotar primero los límites de nuestro estudio.

Por un lado, y en el linde temporal de las dos primeras décadas del siglo xxI, nos centraremos en el microrrelato, cuya condensación estructural favorece la simbiosis semiológica con la imagen. Esto es así porque en ambos 
modos de expresión se verifica el mismo proceso de síntesis que hace que lo connotado sea tan significativo como lo que se denota. Este intenso poder de sugerencia, que Irene Andres-Suárez identifica con el término «elipsis» (2010: 51), constituye un rasgo común con otras formas breves como el verso o el poema en prosa, con las que también comparte la unidad semántica y la concisión (Ródenas, 2007: 73). Tal brevedad, que en palabras de José María Merino está cargada de omisión y sugerencia (2004: 236), determina una escritura ambigua que es también consubstancial a la configuración semiótica de las imágenes (Noguerol, 2008: 185).

La narratividad, otro componente esencial del microrrelato que despoja la historia de elementos descriptivos y la reduce a sus líneas fundamentales (Ródenas, 2007: 73), subyace también en la paradoja ontológica de la imagen, antítesis de tiempo detenido y duración. Esta lógica interna, que opone estasis y diégesis, explica la asombrosa capacidad de las imágenes para sugerir tanto la figuración narrativa como la abstracción simbólica, lo cual explica su profunda analogía expresiva con microtextos como la minificción o el poema en prosa.

Por otro lado, cabe recordar que, en este ámbito textual de lo hiperbreve, tres son las estrategias que, según Andres-Suárez, favorecen la elipsis y la sencillez de la trama: la intertextualidad, el humor y lo fantástico (2010: 79). Y si bien la agudeza irónica que provoca la sonrisa del lector o las alusiones a relatos canónicos son rasgos inherentes a muchos de los textos que valoraremos en nuestro análisis, la prevalencia de lo fantástico es el principal criterio de selección. Sin embargo, y como ha observado Raquel Velázquez (2017: 221), es habitual que en un mismo volumen esta categoría estética coexista con modalidades aledañas como lo maravilloso, la ciencia ficción o el realismo mágico, por lo que consideraremos también algunos microrrelatos no miméticos cercanos a lo fantástico.

A partir de estas coordenadas, el presente estudio tiene como objeto explorar la interacción creadora que microrrelato e imagen establecen en el contexto de lo insólito. $\mathrm{O}$, dicho de otro modo, dilucidar en qué medida cada uno de estos dos sistemas semióticos — el verbal y el visual- está determinado por el otro. Para ello tomaremos como referencia metodológica la noción de intermedialidad, con la que se describen las relaciones de confluencia o divergencia que distintos medios de expresión establecen en términos de narratividad y lenguaje simbólico y en la que se engloban términos más específicos como transmedialidad, multimedialidad o hibridación (Elleström, 2019: 5). Así, tomando este concepto paraguas como una categoría crítica que nos permite analizar compuestos bimediales específicos, el artículo se estructura en función de dos subcategorías de la intermedialidad literaria establecidas por Irina Rajewsky (2005). 
La primera de ellas es la combinación medial, cuya proposición básica es que los elementos que la conforman - en nuestro caso, texto e imagen- están unidos por un vínculo dinámico (2005: 52). Es decir, lejos de configurarse como entidades yuxtapuestas, las ilustraciones y las palabras establecen diversos grados de conexión que oscilan entre la contigüidad y el contrapunto. Así, en este apartado examinaremos la reciprocidad que los microrrelatos de cuatro títulos de la literatura no mimética establecen con las distintas imágenes que los acompañan. Empezaremos con Cuentos malvados, de Espido Freire, cuyas imágenes están semióticamente subordinadas a los microrrelatos, al tratarse de añadidos posteriores. José María Merino firma el segundo texto, Cuentos del libro de la noche (2005), donde su creatividad no se limita a la escritura de los nanocuentos, sino que se plasma también en una variada gama de representaciones visuales. En esta misma línea se inscribe el tercer título, Formulaciones tautológicas (2010), de Felipe Benítez Reyes, donde cada uno de los informes que lo componen constituye la verbalización de un collage, también del autor. Finalmente, fruto de la colaboración entre narradora e ilustradora es Casa de muñecas (2012), de Patricia Esteban Erlés y Sara Morante, en el que la estrecha analogía estética entre palabras e imágenes construye un espacio narrativo dominado por lo siniestro.

La segunda subcategoría identificada por Rajewski es la transposición medial, con la que se refiere al proceso por el que un elemento mediático original da lugar a un nuevo producto, como puede ser el caso de la adaptación cinematográfica de una novela o la representación pictórica de un mito (2005: 51). En este contexto, y para cerrar nuestro estudio, consideraremos Ajuar funerario. El cómic: Difuntos, infantes y monstruos (2018), reelaboración semiótica de un referente clásico del microrrelato fantástico, Ajuar funerario (2004), de Fernando Iwasaki, con guion de Imanol Ortiz e ilustraciones de Beñat Olea.

\section{Combinaciones Mediales}

\subsection{Cuentos malvados}

La trayectoria editorial de Cuentos malvados reproduce el tropo de la metamorfosis, pues entre su primera aparición en Punto de Lectura (2003) y la versión ampliada de Páginas de Espuma (2010), el libro se configuró como un objeto cultural mucho más complejo. Dicha transformación, que no afectó ni 
al número de los textos originales ni a su secuenciación, obedece al añadido de dos elementos nuevos en cada uno de sus siete apartados. En concreto, y como se aclara en la contracubierta, se introdujeron sendas micropresentaciones a cargo «de grandes conocedores de lo brevísimo», así como ilustraciones «de prestigiosos diseñadores». El orden en que se disponen los tres pilares de cada una de estas unidades semióticas —imagen, prefacio y una sucesión de entre 13 y 17 microrrelatos- establece indefectiblemente una gradación de sentido, ya que los dos primeros son vectores unidireccionales que apuntan a los cuentos y crean un marco cognitivo para los mismos. De este modo, tanto las láminas como los preámbulos brindan al lector una serie de impresiones que condicionan el proceso de recepción de los cuentos que siguen.

Los preámbulos definen su naturaleza en función del estilo y la intención de sus autores. Algunos, como Eduardo Berti y Clara Obligado presentan los motivos y la textura simbólica de los microrrelatos que prologan; otros, como Fernando Iwasaki, Ana María Shua y Andrés Neuman adoptan un tono exegético; mientras que José María Merino e Hipólito G. Navarro responden a las ficciones de Espido Freire con otra ficción que se vincula temáticamente a los cuentos de la autora.

En cuanto a los temas del libro, lo monstruoso y el mal son las dos grandes líneas conceptuales que amalgaman la totalidad de los 99 relatos (Díez, 2019: 52; Rodríguez, 2020: 53), sin embargo, cada serie de cuentos gira en torno a un motivo que añade nuevos matices a esta mirada integral. Así, en «El agua», este elemento se presenta como un espacio metafórico, frontera entre la vida y la muerte, y por el que transitan figuras fantasmales, como ahogados y suicidas, o míticas como las sirenas. El hilo temático de la segunda sección, «Ángeles», subraya la oposición entre lo humano y lo angélico, a la vez que fusiona lo cotidiano y lo sobrenatural. La tercera parte, «Las voces», construye el horror desde la sugerencia, mediante presencias malignas invisibles que introducen en el conjunto la evocación del monstruo. La monstruosidad subyace también en las historias de "Arañas y mariposas», pero inscrita en un plano metafísico, pues deriva de polaridades como la inocencia o la maldad o la candidez y el engaño. Sigue «El espejo», donde este objeto simbólico aglutina una serie de juegos poéticos en torno al doble y la refracción. «Los cuentos» constituye un ámbito transgresor en el que, sin abandonar el espacio de lo maravilloso, la autora reescribe leyendas, mitos y cuentos populares, unas veces con cierto toque trágico y otras con ironía y humor. La colección se cierra con «Dentro del laberinto» que, como el epígrafe sugiere, recoge distintas variaciones sobre el Minotauro. El trata- 
miento de lo fantástico oscila, pues, entre la esencialidad de la comprensión humana y la tradición cultural, ya que, si determinados relatos reflejan la angustia ante lo imposible y lo desconocido, otros elaboran motivos típicamente siniestros, góticos o míticos.

El otro componente de estas unidades de sentido, la imagen, aparece al principio, compartiendo página en la portadilla con el título de la sección, lo cual contribuye a cimentar la autonomía semiológica de cada uno de estos bloques. Tal disposición hace que el mensaje lingüístico ejerza una función de «anclaje» sobre el código visual, descrita por Roland Barthes como «un tornillo de fijación» que limita el poder proyectivo de las figuras (1964: 44). Sin embargo, este metalenguaje no puede contener todo el potencial simbólico de las imágenes, que en ocasiones operan en un segundo nivel de interpretación que extrapola lo ficcional a la realidad diegética.

Así ocurre en «El agua», cuya ilustración, obra del polifacético diseñador Jesús del Pozo, es una representación analógica del último cuento de la serie, pues el díptico que configuran la sirena y el hombre de torso desnudo es una síntesis visual de la historia de amor imposible que allí se narra (figura 1). El conjunto incluye además un mensaje codificado con que Del Pozo se implica personalmente para afirmar su sintonía estética con Espido Freire, introduciendo lo que Kress y Van Leeuwen denominan «metafunción textual» (1996: 43). La palabra «Halloween», en la parte superior de la página, connota misterio, oscuridad y muerte, muy en consonancia con el carácter gótico de los microrrelatos; pero el verdadero alcance de esta leyenda solo puede descifrarse mediante la contextualización cultural. «Halloween» es también el nombre de una fragancia femenina que Del Pozo lanzó en 1997, por lo que la simetría gráfica que esta palabra establece con el título del libro, sobre el que aparece, sirve para subrayar la afinidad intermedial entre la obra de ambos creadores. La ilustración contiene además un indicio visual que afianza este mensaje, pues lo que la sirena sostiene en su mano es un frasquito del icónico perfume.

El dibujo de Paco Gil, conocido diseñador de calzado, que abre la sección «Arañas y mariposas», juega también con las fronteras de la intermedialidad, pues su contribución es el boceto de un zapato femenino que aquí se carga de connotaciones temáticas: el tacón es una daga, las tiras de la sandalia son correas y el empeine es una densa tela de araña (figura 2). Aunque el puñal aparece como un arma mortífera en el microrrelato 16, la imagen no se refiere a un cuento específico, sino que ofrece una lectura de las polaridades conceptuales que conforman la urdimbre temática de toda la serie. Así, el tacón-daga, 


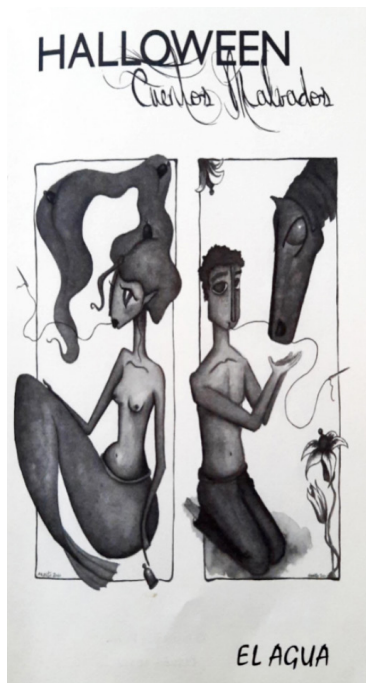

Figura 1 ( ) Jesús del Pozo

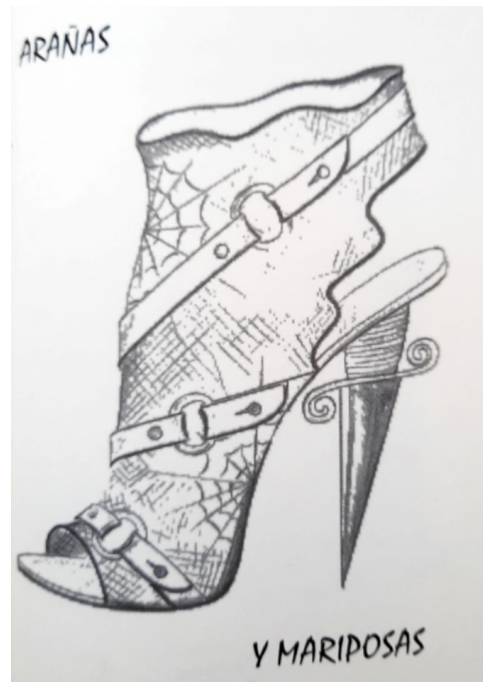

Figura 2 ( P) Paco Gil

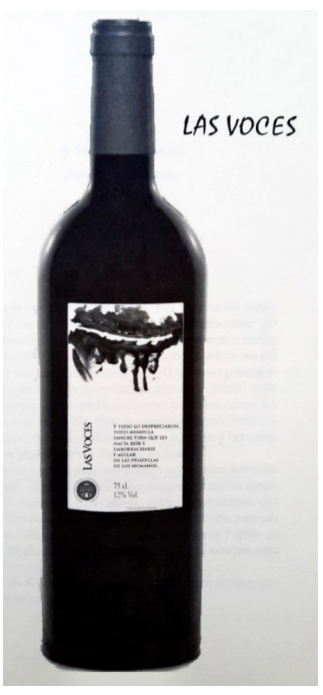

Figura 3 (C) Páginas de Espuma

al aunar elegancia y violencia, representa visualmente la ambigüedad de la belleza, tan destructiva para los que se sienten atraídos por ella (microrrelatos 8,10 y 15) como para los que la poseen (microrrelatos 1,4 y 13). La malla del empeine establece una relación metonímica con otro concepto central de estos textos, la venganza, urdida laboriosamente y con paciencia, sugerida por la forma en que las arañas tejen sus tramas. Las mariposas del título, que en los cuentos poseen una naturaleza ambivalente que fluctúa entre lo hermoso y lo aciago, no forman parte de esta narrativa visual, pero están conceptualmente implícitas en el sistema de oposiciones.

Ambos ejemplos extrapolan al plano estético la convergencia temática entre texto e imagen, pues si la figura de la sirena visualiza el ámbito de lo mítico y lo maravilloso, aunque subrayando también la problemática coexistencia de lo sobrenatural y lo humano, el diseño de Paco Gil captura la mirada transgresora de lo siniestro que disuelve las estructuras de lo familiar. Sin embargo, no todas las ilustraciones del libro llegan a visibilizar la amenaza de lo imposible, limitando su función representacional a la expresión mimética de un motivo o un concepto.

En otros casos, el elemento insólito aparece normalizado en una representación híbrida, como sucede en «Las voces» (figura 3). El funcionalismo de la imagen, que sigue el patrón de un cartel publicitario, ofrece un agudo con- 
traste con la atmósfera angustiosa de los cuentos, donde la presencia acechante e invisible del monstruo se sustenta en motivos como la niebla, las sombras, la oscuridad o el murmullo perverso de las voces. Por supuesto, tal disparidad estética, que opone minimalismo contemporáneo y tradición gótica, es solo aparente. La verdadera ruptura semiótica se produce en el seno de la imagen con la incorporación, en la etiqueta de la botella, de dos mensajes que destruyen la convencionalidad de su formato y deslizan una nueva perspectiva de interpretación. Uno de estos dos indicios es la leyenda que reproduce las últimas líneas del relato final de la serie, tras las que se adivina la figura del licántropo: «Y todo lo despreciaron, todo menos la sangre tibia que les hacía reír y emborracharse y aullar en las pesadillas de los humanos» (2013: 65). Este inserto introduce una nueva retórica visual que permite descodificar el mensaje icónico de la parte superior de la etiqueta: una mancha borrosa que el lector identifica ahora como sangre y cuyo simbolismo puede extenderse también al contenido de la botella. De este modo, y siguiendo la nomenclatura de Barthes, este mensaje lingüístico no solo ejerce una función de «anclaje» que permite descodificar la imagen denotada, sino que confiere a la misma un intenso poder de connotación.

\subsection{Cuentos del libro de la noche}

Para intentar descubrirlos debo despertarme en medio de la noche. Me levanto, recorro despacio el pasillo. Nunca enciendo las lámparas, llevo en la mano una linterna pequeña. Su resplandor escaso, subrepticio, me ayuda a encontrarlos, a veces. Con el tiempo he comprendido que viven en lo oscuro como nosotros en la luz. Una noche vislumbré la figura de un hombre sentado al fondo del salón, leyendo el periódico. Otra vez la linterna me permitió atisbar el cuerpo huidizo de una mujer en el recibidor. Otra noche, al pasar ante mi cuarto de trabajo, me pareció que había un bulto sentado delante del ordenador. El tiempo pasa y ya no puedo recordar si alguno de estos habitantes de la casa en la noche ha escrito en mi ordenador los textos que ahora considero míos (Merino, 2005: 9-10).

Con este microrrelato, «Página primera», se abre la serie de 85 minificciones que componen los Cuentos del libro de la noche. Y si iniciamos con él este apartado, es porque nos revela las claves del entramado filosófico y representacional que articula el resto de la obra. La historia transcurre en el espacio de lo nocturno, territorio de lo desconocido donde se adivinan presencias inexplicables y cuya estructura simbólica se funda en el dinamismo 
de la polaridad; pues del mismo modo que no hay noche sin día, la oscuridad es el reverso de la luz. Lo visible y lo invisible coexisten en la penumbra de la casa y el protagonista, al sorprender a los habitantes que la ocupan cuando él duerme, intuye en ellos a su otro yo: su ser creativo, el que escribe y se disgrega en sus personajes. El relato oscila así entre el misterio y la reflexión metaficcional, por lo que además de ser una metáfora de todos aquellos contrastes que nos ofrece el imaginario cultural de lo nocturno, se configura también como un tropo de la subjetividad creadora y la dualidad interior.

Cada uno de los cuentos de este libro viene acompañado de una ilustración con la que forma una unidad significativa. Todas las imágenes, creadas por José María Merino «para incitar al lector a detenerse en cada página y cada microrrelato», establecen una relación de complementariedad con los textos (Andres-Suárez, 2010: 271). La que corresponde a «Página primera»se reproduce también en la portada, lo cual intensifica todavía más el valor referencial de esta primera combinación medial de la serie. Consiste en un bosquejo geométrico donde varios cuadrados se superponen para crear una impresión de profundidad, perspectiva y volumen (figura 4). La frialdad de las líneas rectas queda rota por la presencia de una silueta humana que, de pie y en el ángulo interno de uno de los cuadrángulos, construye de inmediato la idea de umbral, un motivo asociado típicamente a la entrada del elemento fantástico (Roas, 2011: 35; Parramon, 2020: 291). Sin embargo, y como Rosemary Jackson ha destacado, lo fantástico posee también profundas implicaciones psicológicas (2003: 14), que en esta escena se materializan en la proyección de la sombra, con la que se introduce una dimensión subjetiva al visualizar lo que Jung identificó como el doble psíquico, la parte que uno ignora de sí (2004: 70-73).

El esquematismo del diseño reduce a lo esencial las variables fundamentales del texto - la frontera entre dos dimensiones, la antítesis de noche y luz, la dualidad interior- dando así una forma visual a la abstracción. La geometría del cuadrángulo, o en ocasiones la esfera, visualiza también la esencialidad conceptual en otros relatos como "Cuerpo rebelde», «Divorcio», «Reencuentro», «Las cuatro y media» o «Posdata». Este último (figura 5), que aparece al final del libro, presenta una gran similitud con el dibujo de «Página primera», lo cual enfatiza el paralelismo temático entre ambos textos, identificado por Ángeles Encinar como la posibilidad de otras vidas (2011: 205), e introduce en la estructura del libro cierta impresión de circularidad. 


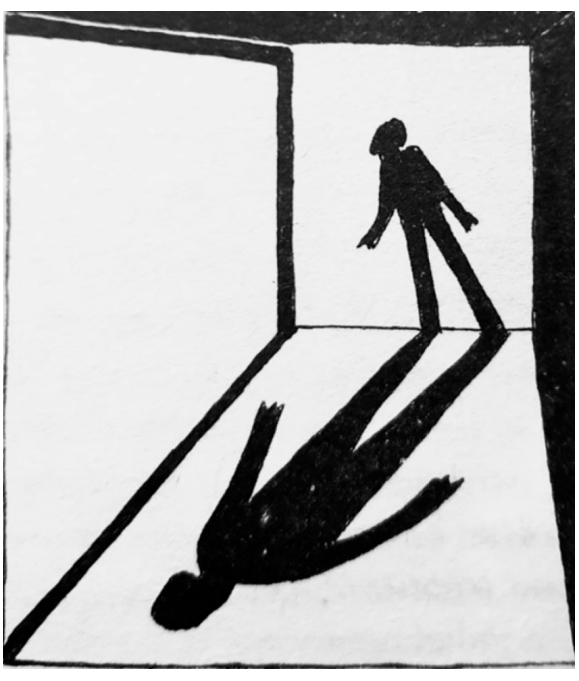

Figura 4

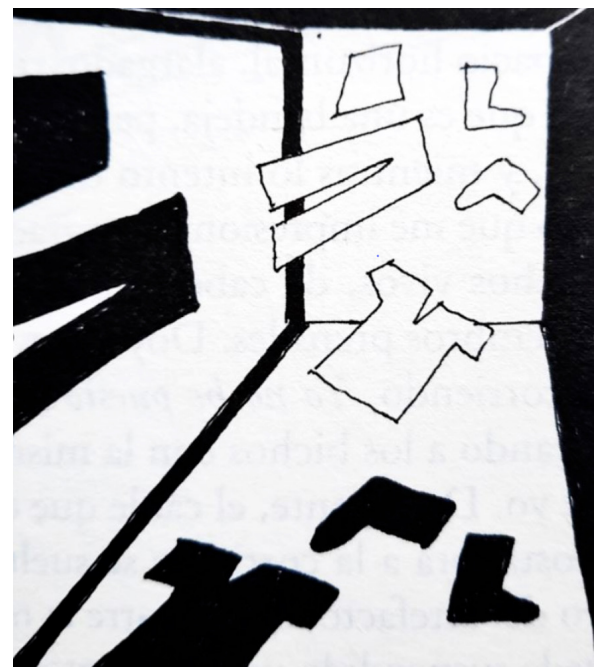

Figura 5

Esta no es la única técnica que Merino aplica a la creación de sus imágenes; incluye también fragmentos de obras pictóricas y fotografías cuidadosamente manipuladas, así como collages o ilustraciones de diversas procedencias. Afortunadamente, contamos con valiosos estudios sobre el universo iconográfico de los Cuentos del libro de la noche. A los ya citados trabajos panorámicos de Andres-Suárez (2010) y Encinar (2011) se añade el de Christoph Rodiek (2012), quien profundiza en la unidad significativa que dos cuentos de la serie establecen con sendas pinturas bien conocidas: Las Meninas, de Velázquez, y Nighthawks, de Edward Hopper. Los tres concluyen que las imágenes enfatizan el sentido de los textos y destacan conceptos relacionales como visualización (Encinar, 2011: 215) y complementariedad (Rodiek, 2012: 199). Andres-Suárez sistematiza además aquellas abstracciones que la imagen configura plásticamente: distintos órdenes del tiempo y la realidad, la extrañeza y temas de carácter ético-social (2010: 276-278).

Sin embargo, no solo las imágenes del libro poseen una función referencial explicativa, sino que esta se da también en los microrrelatos, estableciendo una interacción que Agosto ha denominado «narrativa interdependiente», un modelo teórico basado en la complementación mutua de ambos elementos (1999: 269). Un ejemplo de esta forma de relación lo ofrece la serie titulada «El despistado», en la que Merino retoma el concepto de umbral para narrativizar la conciencia de la muerte, y donde la imagen se concreta en un 
dibujo esquemático (figura 6), un collage (figura 7) y el fragmento de un cuadro de Brueghel, El triunfo de la muerte (figura 8). La tríada presenta tres momentos sucesivos por los que pasa un hombre que no sabe que está muerto: el deceso, su taciturno deambular por el cementerio y su despertar en el ataúd.

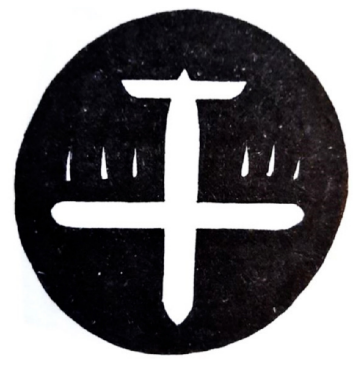

Figura 6

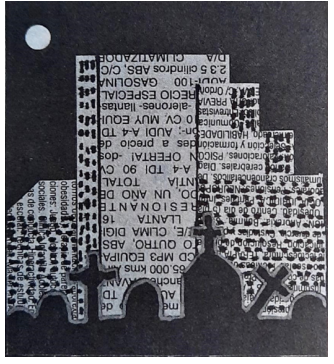

Figura 7

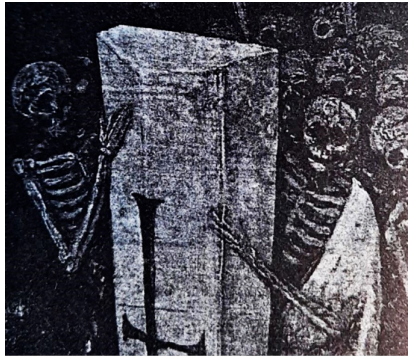

Figura 8

La focalización interna de los tres cuentos desliza en la historia una dimensión espaciotemporal que no se corresponde con la materialidad de la diégesis, por lo que el protagonista nos describe en primera persona una situación que no entiende y que constantemente trata de racionalizar. Así, la primera frase de «El despistado (uno)», «el avión ha aterrizado», establece un marco situacional preciso, pero cuando el viajero recoge sus cosas para salir tras un «horroroso vuelo» lleno de zarandeos y ruidos extraños, es la carcajada grotesca de los demás pasajeros, que siguen en sus asientos, lo que provoca en él la confusión. $\mathrm{Y}$ aunque en cierto modo el título de la serie funciona como un elemento de desambiguación, es la expresividad del dibujo lo que revela al lector esa realidad diegética que el narrador de la historia no logra comprender. La esencialidad del diseño, con la silueta del avión y los pequeños trazos que indican el movimiento de la nave en caída libre, contradice la aserción que abre el microrrelato y visualiza para el lector la epifanía a la que el protagonista no puede acceder. Del mismo modo, el dibujo sería incomprensible sin el texto previo, por lo que la relación que ambas unidades establecen es simétrica.

Parecido proceso se verifica en «El despistado (dos)», donde, en su paseo por una ciudad desconocida, el protagonista se cruza con varias personas que le recuerdan a viejos conocidos y familiares muertos. En este relato, nada rompe la coherencia del espacio percibido por el narrador, que nos habla de parques, de rampas de garaje y de la austeridad inhumana del hotel en que se aloja, por lo que la confusión que dominaba el cuento anterior se transforma ahora en 
intensa melancolía. No obstante, si bien el texto constituye una unidad de sentido que no requiere más explicación, presupone también dos realidades superpuestas que se revelan en la imagen. Construida con el esquematismo de los cuadrángulos y las siluetas, la ilustración presenta dos planos metafóricos que visualizan esta frontera entre la vida y la muerte por la que deambula el despistado. Al fondo, los bloques de viviendas de una ciudad, y en primer plano los contornos inequívocos de las cruces y las lápidas de un cementerio. Las dos realidades que se solapan en la historia — la subjetiva y la diegética- se superponen con claridad en la imagen para que el lector pueda establecer las correspondencias pertinentes entre lo que el protagonista cree ver y el lugar en el que verdaderamente se encuentra. Esta forma de interacción creativa entre texto e imagen se basa también en la complementariedad mutua; sin embargo, el impacto visual del collage se elabora según la subcategoría de la «aumentación» al añadir un nuevo nivel de significado (Agosto, 1999: 270). Los recortes rectangulares de periódico que conforman los edificios proceden de la sección de anuncios, por lo que esa trivialidad de lo cotidiano en la que el protagonista sigue atrapado contrasta aún más con la triste solemnidad de las cruces inclinadas.

«El despistado (tres)» fusiona también la textualidad desdoblada de lo percibido - la estrechez de una cama - y lo latente - la cavidad de una tumba-, y si bien podría leerse como un relato siniestro en el que el enterramiento en vida se configura como una horrible pesadilla, la ilustración que lo acompaña redirige el sentido hacia su nivel diegético. Merino recurre aquí a un pequeño fragmento del ya citado cuadro de Brueghel, en el que una hueste de esqueletos sujeta un féretro, dos símbolos culturales con los que universalmente se significa la muerte y con los que, como sucedía en «El despistado (uno)», se visualiza para el lector aquello que el protagonista todavía no sabe. Además, al conocimiento antropológico de los emblemas de la muerte, se agrega un conocimiento cultural, pues, aunque la ilustración solo muestra una sección de El triunfo de la muerte, Merino juega con la figura retórica de la sinécdoque al facilitarnos al margen el nombre del artista, lo cual permite al lector identificar la pintura. De este modo, el mensaje lingüístico dilucida también el sentido de la imagen.

\subsection{Formulaciones tautológicas, informes y collages}

«Hay sentimientos estéticos que solo pueden intuir los sombreros que han perdido la cabeza», leemos en el prólogo de Formulaciones tautológicas (2010: 9). Afortunadamente, para entrever la intención artística y conceptual 
de este libro, basta con detenerse un momento en el complejo enunciado del título. Lo que este nos revela es una estructura relacional en la que informe y collage constituyen una serie de unidades semióticas, las formulaciones, que responden a la dinámica de la reduplicación, como nos indica la figura de la tautología. El título anuncia también el tono lúdico que impregna todo el libro y se materializa en cada una de sus páginas, tanto en el surrealismo de los collages y la ironía absurdista de las historias, como en la ironía del prólogo.

Por ello debemos tomar la frase que abre el prefacio - sombreros que han perdido la cabeza - como una declaración estética, pues la inversión de los términos representa metafóricamente el proceso creativo de estas formulaciones, en las que predomina la normalización de lo absurdo y lo desproporcionado. A lo largo de este preámbulo se insiste, además, en la necesidad de liberar la metáfora de su estrecha red de correspondencias para hacer de la misma el objeto último de la creación: «No sabemos con exactitud de qué — ¿quién podría saberlo?-, pero nuestro ensueño sería ese: transformar el sombrero en metáfora. De algo. Y nos daríamos por satisfechos si entre todos lográsemos convertirlo al menos en metáfora de sí mismo: el sombrero como metáfora del sombrero (...) el prólogo como metáfora del sombrero» (2010: 11). Bajo este despropósito aparente subyace una sofisticada construcción metafórica en torno al sentido de las ficciones y su discutible relación con la realidad. Y esto es, precisamente, lo que esta obra cuestiona de principio a fin. No solo mediante la sintaxis fragmentada del collage o la causalidad disparatada de los informes, sino también en la concepción de este prólogo, pues quien lo firma -Felipe Blázquez - es «un alter ego (o una vida improbable) de Benítez Reyes» (Pérez-Bustamante, 2014: 348). De este modo, y haciendo nuestras las palabras de Gérard Genette, la funcionalidad de este prólogo ficticio consiste esencialmente en su ficcionalidad, al introducir en el libro otra dimensión ilusoria que ni siquiera pretende ser un simulacro (1987: 256).

El proyecto, considerado por Ana Sofía Pérez-Bustamante como una pequeña rareza en la obra de Felipe Benítez Reyes (2014: 335), surgió a partir de una sugerencia de Juan Bonilla, quien propuso al autor la publicación de algunos de sus collages (2014: 337). Para cada uno de ellos, veintiuno en total, Benítez Reyes escribió un breve relato que plasma la narratividad latente de las imágenes, algo que de manera inevitable condiciona la recepción del componente visual. A esto se suma la disposición de los elementos textuales y gráficos, ya que los informes preceden a los collages, invirtiendo así el orden en que ambos fueron creados y presentando estos últimos como una ilustración de los primeros. Y aunque el texto ejerce una función de «anclaje» sobre la imagen al limitar su 
capacidad proyectiva, también es cierto que los microrrelatos enfatizan la narratividad de los collages al intelectualizar su abstracción, verbalizar su dialéctica interna y crear una lógica causal para su tiempo y espacio fragmentados.

El referente estético visual es Marx Ernst (Pérez-Bustamante, 2014: 337), creador de los romans-collages (1929-1930), tres novelas gráficas sin coherencia narrativa compuestas a partir de recortes de novelas detectivescas decimonónicas. Benítez Reyes no solo se inspira en la técnica de Ernst, sino que también recurre a ilustraciones de finales del XIX como material de base para sus composiciones. Con frecuencia, el fondo es un grabado al que superpone figuras humanas, animales, híbridos aberrantes u objetos que rompen la isotropía conceptual, bien sea por la desproporción de su escala o por el efecto inquietante de lo monstruoso. De este modo, las imágenes de estas formulaciones establecen una línea de continuidad con la deriva grotesca del surrealismo, que Wolfgang Kayser no dudó en calificar de «grotesco fantástico» (2010: 288), si bien Roas rechaza esta asimilación al considerarla reduccionista (2011: 67).

La conexión formal entre Ernst y Benítez Reyes sugiere también cierta sincronía ideológica, pues del mismo modo que Ernst subvierte las imágenes de un mundo obsoleto para cuestionar determinados roles y relaciones de poder en la sociedad de su tiempo (Humphreys, 2006: 378), Benítez Reyes toma la matriz cultural del XIX para construir una sátira extrapolable a nuestros días. Las láminas que sirven de fondo a sus collages, entre las que encontramos estampas arquitectónicas y urbanísticas, escenas de interior o entornos naturales, connotan impresiones como orden, equilibrio o belleza que, invariablemente, se ven amenazadas por la entrada de elementos discordantes.

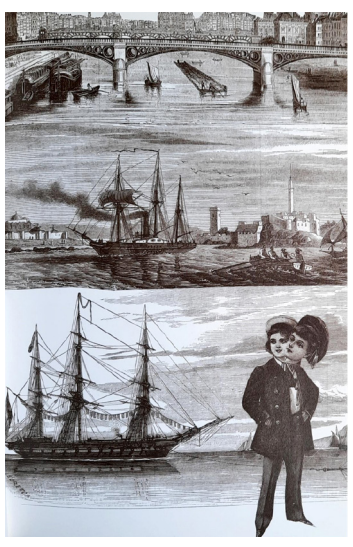

Figura 9

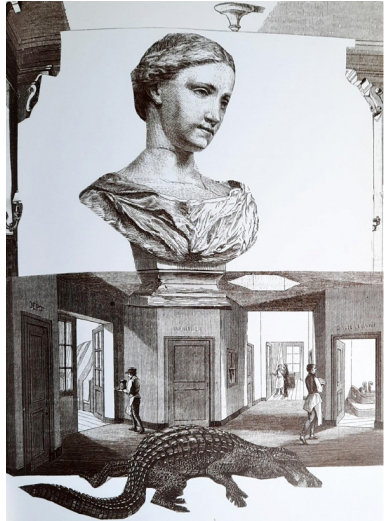

Figura 10

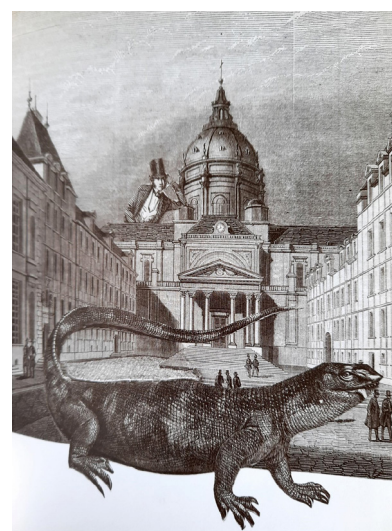

Figura 11 
Así, en «El mar» (figura 9), además de contar con la inquietante presencia de un niño bicéfalo, se contraponen tres planos espaciales que sugieren un desdoblamiento infinito. También encontramos dos niveles yuxtapuestos en «El hospicio» (figura 10), donde la aparente normalidad de las dependencias del área inferior entra en conflicto con las dimensiones colosales del busto que la presiden y con el cocodrilo que avanza por los pasillos. Parecido choque estético y conceptual se da entre el urbanismo racionalista de «La iguana» (figura 11) y la disonancia que producen el enorme saurio plantado en medio de la plaza o el caballerete que asoma tras los edificios. La heterogeneidad y la disolución del espacio provocan a la vez la sonrisa y el horror, lo cual hace de estos collages diseños intensamente grotescos. Y, si bien estos no pueden calificarse como puramente fantásticos, el surrealismo que los impregna construye una realidad autónoma en la que se borran los límites entre lo real y lo irreal (Roas, 2011: 39)

Esta contradicción visual de lógica y disparate se traslada también a los informes, la otra mitad de estas combinaciones mediales. Los relatos se hilvanan con argumentaciones descabelladas, situaciones ridículas y toques tragicómicos, recreando así el lenguaje del absurdo (Bennet, 2015: 19). Con prosa sencilla, coloquial y denotativa el autor normaliza las discordancias de las imágenes y desliza cierta intención crítica cargada de humor e ironía. Por ejemplo, el protagonista de «El mar» resulta ser, «como todos los niños bicéfalos de Baltimore», un lector empedernido de ficciones que acaba sucumbiendo a la artificiosidad del pequeño mundo a su medida que su padre, el magnate Dowson, había construido para él. De manera similar, el establecimiento de «El hospicio», que en el collage evoca la imagen mental de un balneario, paradigma del bienestar burgués, es en el informe el Hospicio Ferrandis, una institución benéfica presidida por el busto de su protectora y equipado con un cocodrilo «para que aquel recinto no se viera privado de su componente indispensable de horror latente» (2010: 22). Por último, la paradoja que producen en el collage de «La iguana» el contraste entre la perfección de las líneas arquitectónicas y lo aberrante, se perfila en el informe como una parábola de la arbitrariedad de la justicia. El mar artificial del niño bicéfalo, el cocodrilo o la iguana pueden verse, mediante este proceso de conceptualización, como metáforas de la inautenticidad, el horror o la injusticia, pero no debemos olvidar que las formulaciones tautológicas de este libro solo nos ofrecen una de las historias latentes en cada collage, por lo que estas metáforas, como el tropo del sombrero, son figuras con más de un sentido. 


\subsection{Casa de muñecas}

Las minificciones de Casa de muñecas, el primer título de narrativa hiperbreve de Patricia Esteban Erlés, nacieron como un objeto digital. La autora se planteó un verano el desafío de crear un «boceto de relato diario, a partir de una imagen» para compartirlo en su cuenta de Facebook, donde sigue publicando este formato con regularidad (Jiménez, 2018: 215). Y fue en este foro público, determinante en la composición y recepción de los textos, donde entró en contacto con la ilustradora Sara Morante. Juntas trabajaron para seleccionar y trasladar estos cien minicuentos desde la hipermedialidad de las redes sociales al papel, acompañados esta vez de nuevas imágenes. El resultado es un libro de intensa belleza en que el cronotopo doblemente siniestro de la casa de muñecas funciona como un espacio semántico y como un sistema estructural.

Por una parte, las categorías de lo ominoso y lo gótico dominan la estética y las formas de representación, no solo por la recurrencia de algunos de sus motivos clásicos como el entorno doméstico, las muñecas, los fantasmas o el doble, sino por el horror que permea sus historias (De la Varga, 2015; Sánchez, 2015; Abello, 2019; Calvo, 2019; Díez, 2019). Asimismo, temas como la angustia provocada por la conciencia del tiempo, el trauma o las incertidumbres de la identidad, implícitos en la expresión de lo siniestro, construyen en esta obra una subjetividad femenina que oscila entre la alienación y el empoderamiento (Álvarez, 2019; Velázquez, 2019).

Por otra parte, la arquitectura de la casa es el marco estructural en que se inscriben los relatos, distribuidos en once áreas semánticas que en el libro se materializan en apartados bien diferenciados: el cuarto de juguetes, el dormitorio infantil, el dormitorio principal, el cuarto de baño, el salón comedor, la cocina, la biblioteca, el desván de los monstruos, la cripta y los exteriores. Sin embargo, aunque cada una de estas dependencias constituye un pequeño núcleo de significados, no son compartimentos estancos, ya que los temas y motivos que las caracterizan están también en suspensión en las otras habitaciones de la casa. El índice refleja con claridad esta organización interna del libro, pero lo que verdaderamente plasma su textura abstracta es la ilustración a doble página que aparece a continuación, donde la realidad fragmentada de esta casa de muñecas se percibe también como un todo unitario (figura 12). 


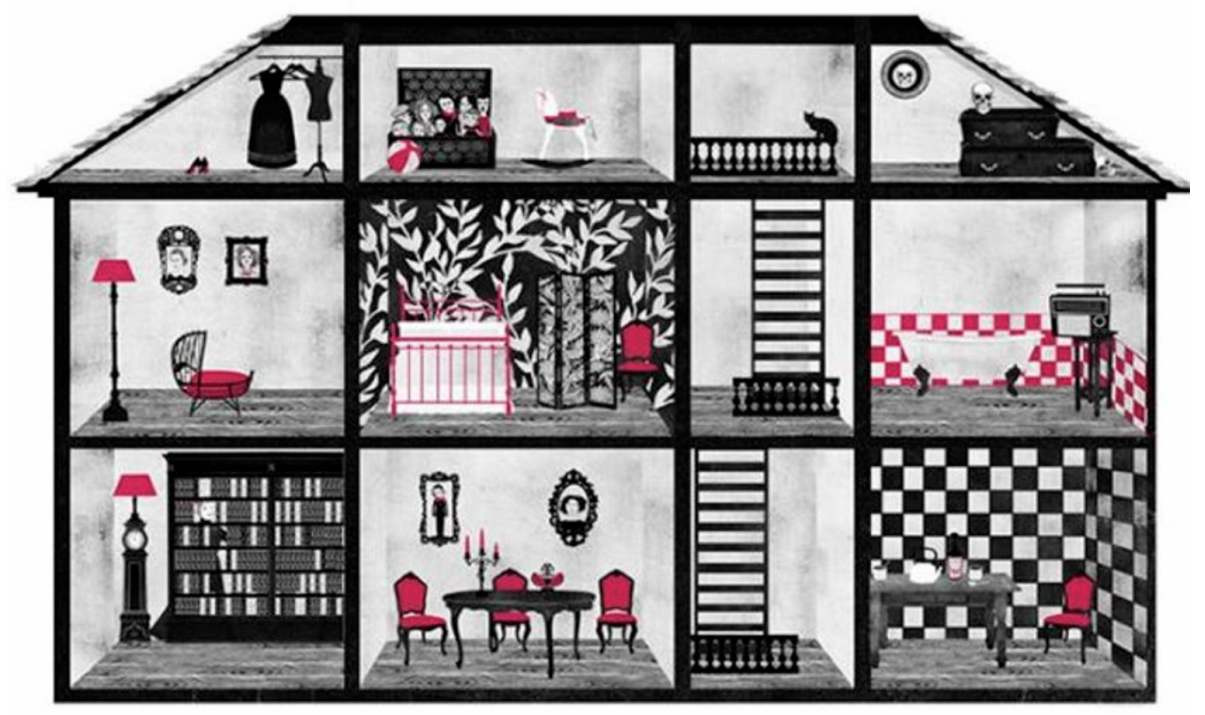

Figura 12

Según Laurence Bardin, la primera aprehensión de una imagen se produce de manera global y sintética (1975: 99). Por ello, y por su contigüidad con el índice, esta ilustración desempeña una importante función estructural, ya que visualiza el espacio simbólico del texto y proyecta la idea de un sistema dinámico en el que sus componentes están interrelacionados. Asimismo, la silueta del edificio y el diseño de los interiores, de inspiración victoriana, connotan un segmento temporal estrechamente vinculado a la estética de lo gótico, dominante en el libro, lo cual consolida las impresiones sugeridas por determinados epígrafes del índice, como «Cripta» o «Desván de los monstruos», y abre para el lector un extenso campo de sugerencias. Algo similar revela la dimensión cromática, pues el toque de color que destaca sobre el negro y el gris en cada una de las habitaciones es un leitmotiv presente en todas las ilustraciones del libro, la tipografía y las guardas. Y aunque el espectador todavía no lo sabe, el mensaje de este tono magenta es intensamente ideológico, pues con él se alude al subtexto feminista y transgresor de los cuentos (Jiménez, 2018: 215).

Sin embargo, añade Bardin que de manera simultánea el individuo selecciona también determinados elementos de la imagen que lo llevan a un nivel más profundo de interpretación (1975: 99). Este proceso sincrónico que combina lo general y lo particular produce aquí un efecto desestabilizador, 
ya que el campo referencial de la miniatura, vinculado emocionalmente a una visión nostálgica de la infancia y de la historia (Stewart, 1993: 69), es subvertido por varios detalles que construyen el discurso de lo ominoso. Así, a motivos característicos de lo siniestro como los retratos de las paredes que insinúan el doble, las muñecas apiñadas en el arcón del cuarto de juguetes o las naturalezas antropomorfas del maniquí de costura y el solitario vestido que cuelga de una percha, se agregan objetos grotescos como las calaveras del desván, gestos cargados de misterio como la figura femenina que nos observa semiescondida tras los libros, o alusiones intertextuales como ese gato negro que tanto nos recuerda a Poe.

También las imágenes de las portadillas que introducen cada uno de los apartados del libro poseen esta doble función, estructural y connotativa, ya que no solo cohesionan el conjunto estableciendo una conexión visual entre la parte y el todo, sino que resignifican el sentido del icono introductorio. Por ejemplo, basta con comparar el fragmento correspondiente al dormitorio infantil de la ilustración inicial (figura 13) con el dibujo que encabeza dicha sección (figura 14) para apreciar el efecto de espejo distorsionado que se establece entre ambas escenas, pues si bien se mantiene uno de los objetos centrales como marca de continuidad, en este caso la cunita, la substitución del niño por el muñeco decapitado inevitablemente provoca una profunda sensación de desasosiego.

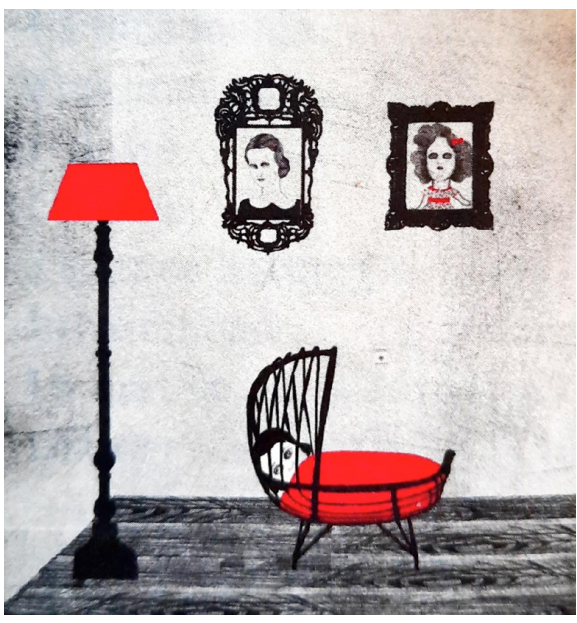

Figura 13

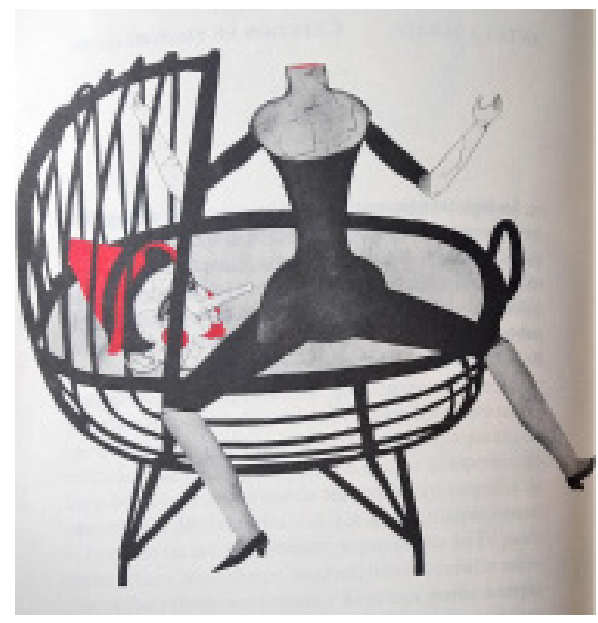

Figura 14 


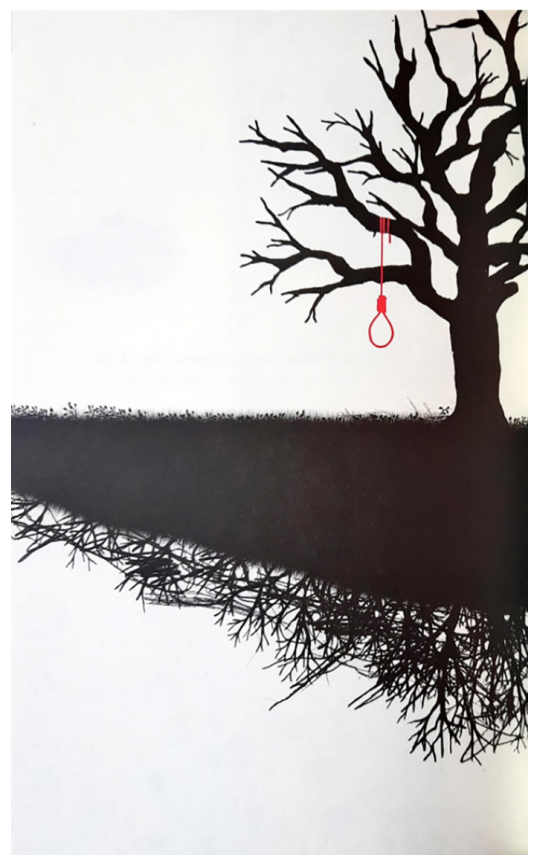

Figura 15

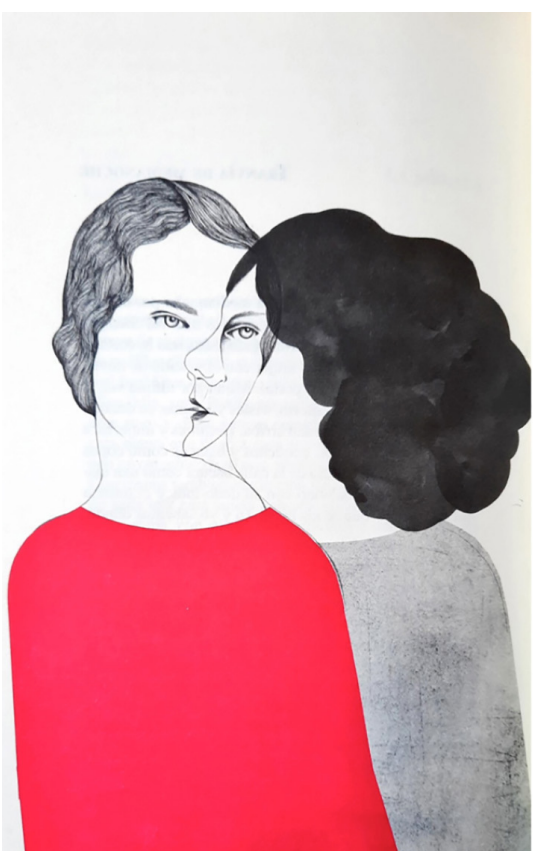

Figura 16

Como ha observado Ana Abello, las ilustraciones «intercaladas entre las minificciones originan un universo simbólico igual de relevante que el texto» (2019: 44), algo que también ha manifestado la propia autora al calificar el trabajo de Morante como una interpretación personal que completa la escritura (Jiménez, 2018: 215). En efecto, aquellos microrrelatos que aparecen acompañados de imágenes establecen una relación convergente y simétrica por la que ambos sistemas semióticos se complementan. Así, lo vemos en «El columpio», cuyo mensaje críptico se esclarece gracias a la subjetividad de la ilustradora: "Me acuerdo de cuando confundimos la muerte con un columpio» (figura 15). El dibujo desencadena así un proceso cognitivo de identificación entre la soga y el columpio que intensifica todavía más el efecto siniestro (Gabbard, 2017: 96). Del mismo modo, en la imagen de «Secreto» (figura 16), la superposición de los dos rostros integra conceptualmente dos planos de la conciencia - la consciente y la subconsciente- y de la realidad —el mundo natural y lo sobrenatural — al tiempo que visualiza en la página la sugerencia del fantasma: «Me lo contó mi peor amiga en el recreo: Sabes, tú también vas a morirte». 
3. Transposición medial: de Ajuar funerario (2004) a Ajuar funerario.

EL CÓMIC (2018)

Si hay un concepto básico en el proceso creativo de la transposición medial es el de «adaptación», término que ha generado un amplio caudal de estudios en torno a las migraciones textuales que se producen entre medios diversos como la narrativa, el cine, el teatro, la ópera, la animación o el cómic. Un procedimiento de tal complejidad implica necesariamente seleccionar, interpretar, simplificar o amplificar el texto de partida para crear otro producto que lejos de ser una mera imitación del original, es el resultado de una profunda transformación (Rajewsky, 2005: 51). Repetición y diferencia son, pues, dos nociones encontradas que conforman la naturaleza doble de las adaptaciones, ya que si por un lado constituyen un reflejo de la obra que versionan, por el otro son objetos estéticos por derecho propio, lo cual compromete la noción de «fidelidad» como criterio de análisis (Hutcheon, 2006: 6). Por todo ello, al examinar las estrategias de transcodificación que nos llevan de los microrrelatos de Iwasaki al universo del cómic, no consideraremos la retórica de la fidelidad en términos de duplicación del discurso original, sino en términos de interpretación y reproducción del sentido. Después de todo, y como sostienen Kress y Van Leeuwen, cada medio tiene sus propias posibilidades y limitaciones de expresión (1996: 19). Por ejemplo, el carácter denotativo de los dibujos del cómic — con sus primeros planos y expresiones faciales— favorece la caracterización de los personajes, pero no todos sus pensamientos, impresiones o recuerdos se pueden trasladar a las imágenes. Se da también el caso inverso, pues la minuciosidad con que algunas viñetas construyen el espacio para crear un efecto de realidad es impensable en el microrrelato, donde la síntesis y la sugerencia prevalecen sobre la descripción.

En el contexto del cómic, la interacción creadora entre texto e imagen está determinada por el carácter híbrido del medio, que hace que ambos sistemas semióticos estén estructuralmente conectados según distintos niveles de integración (Cohn, 2013: 36). Cierto es que la palabra puede estar ausente en ocasiones, pero esa ausencia añade también matices a la comunicación, por lo que, incluso de manera implícita, texto e imagen conforman una unidad de significado que se materializa en cada una de las viñetas de la historia. No obstante, la totalidad del sentido solo puede alcanzarse de forma secuencial, siguiendo la sucesión significativa de las viñetas, lo cual construye una narrativa verbovisual que, más allá de la especificidad del cómic, establece un punto de conexión básico con otras formas narrativas como el microrrelato. 
Este principio constitutivo común, la narratividad, nos permite articular los procesos que intervienen en el trasvase de un medio a otro. Sin embargo, es preciso recordar que el primer paso hacia la reformulación semiótica de los microrrelatos de Iwasaki fue la selección de los textos, a cargo de Imanol Ortiz, el guionista del proyecto. Ortiz escogió dieciocho títulos que organizó en tres secciones — «Difuntos», «Infantes» y «Monstruos»— de seis historias cada una, con lo que la estructura general de El cómic reproduce el número de la Bestia (6-6-6). Además de este toque de humor negro, tan del gusto de Iwasaki, la selección temática sugiere también una profunda comprensión del texto original, pues el mundo de ultratumba, la inquietante calidad del horror provocado por los niños y lo aberrante son tres núcleos semánticos fundamentales en el libro de Iwasaki.

A pesar de las diferencias semióticas que separan la ficción verbal de la hibridez del cómic, los engranajes que articulan el contenido de la historia y las estructuras de transmisión narrativa son comunes a todas las formas de ficción (Chatman, 1978: 26), por lo que aspectos como las secuencias, la focalización o la temporalidad nos permiten establecer un marco comparativo para los cuentos de Iwasaki y la reescritura de Ortiz. Ilustraremos estas convergencias y disparidades con «Peter Pan», un relato que, si bien Francisca Noguerol califica como el único realista de la serie de Iwasaki (2009:12), presenta el mundo de la fantasía como una dimensión más de la realidad natural, pues como ha observado Raquel Velázquez, el niño protagonista es incapaz de distinguir entre ambos planos y actúa según los parámetros de lo fantástico (2012: 183). La historia se construye desde la perspectiva infantil y a partir de la vulnerabilidad y el miedo, ya que ese niño que cierra las persianas de casa para que el hombre lobo no se meta en su cuarto, teme también a los pequeños monstruos que cada día le pegan en el colegio. Frustrado por no ser él también hijo de un villano o un superhéroe, como los compañeros que lo maltratan a diario, decide convertir a su padre en el Capitán Garfio amputándole una mano con el hacha de cortar la carne mientras este duerme.

Uno de los rasgos estructurales más importantes del microrrelato es el título, pues guarda una relación dialéctica con la historia al enfatizar alguno de sus aspectos constitutivos (Andres-Suárez, 2007: 30). Las historietas de El cómic subrayan esta peculiaridad al dar a los títulos un espacio privilegiado, en las páginas pares del libro, en tipografía de grandes dimensiones y acompañado únicamente de un objeto simbólico referido a algún aspecto de la trama, con lo cual no solamente se enfatiza la interacción dialógica entre título y relato, sino también entre imagen y texto. En «Peter Pan» el efecto que produ- 
ce el garfio se intensifica todavía más con el uso de la doble página y el reguero de sangre que anuncia el truculento final (figura 17).

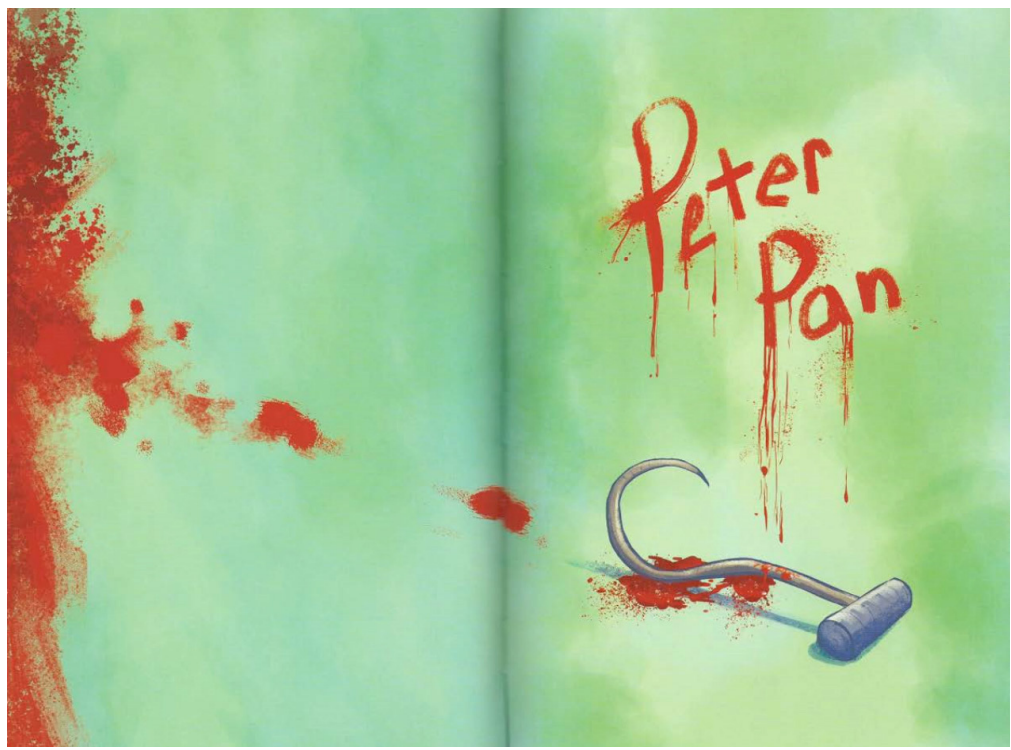

Figura 17

Determinadas fuerzas del relato como la focalización o las secuencias narrativas, que tan determinantes son en el universo puramente textual, se materializan en el cómic mediante el uso combinado de palabras e ilustración (figura 18). Las quince viñetas de esta doble página, donde se plasma el desarrollo de la historia, no solo reduplican segmentos del discurso del microrrelato, sino que agregan una dimensión visual descriptiva que contribuye a la caracterización del protagonista. Destacan, en este sentido, dos dibujos con los que los creadores del cómic enfatizan la vulnerabilidad y aislamiento de este niño: el del pequeño con su inhalador y el primer plano de la mano que sostiene indolentemente un cigarrillo junto al rótulo «Mamá no dice nada» que ni siquiera figura en el texto original. Esta disonancia productiva se contrarresta con la omisión de la analepsis con que Iwasaki describe el momento de la amputación y que los creadores del cómic reproducen mediante ilustraciones. No menos interesante es la plasmación de la temporalidad del cuento en la página de la derecha, donde se subvierte la lectura horizontal de las viñetas para obligarnos a leer en el sentido de las agujas del reloj, lo cual traduce a imágenes la fusión de tiempos verbales y la tensión creciente con que Iwasaki culmina su relato. 


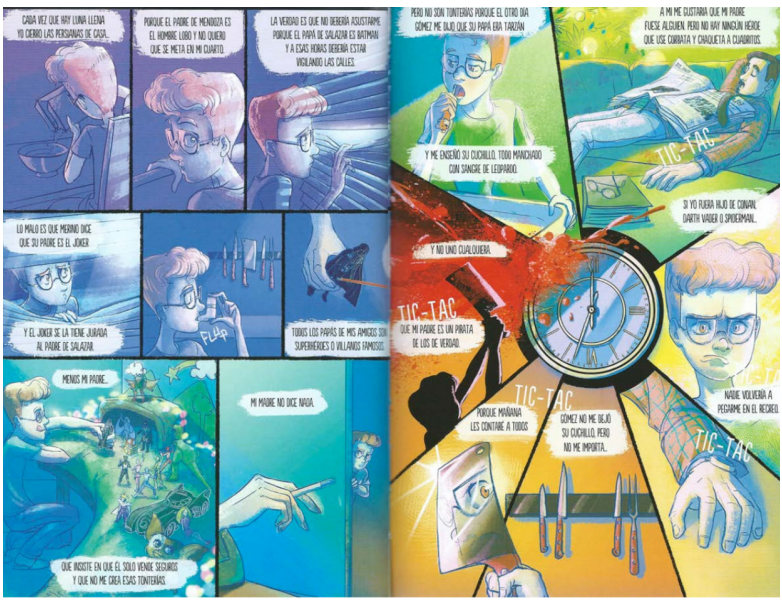

Figura 18

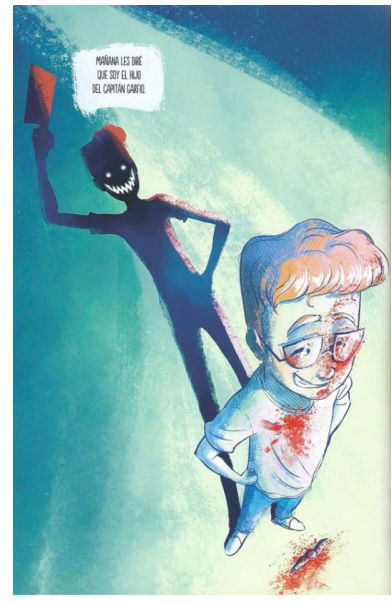

Figura 19

El impactante final de la historia se visualiza en el cómic mediante el cambio de página, mecanismo muy usado para introducir sorpresa $\mathrm{u}$ horror (Pina, 2020: 2014). Sin embargo, la última imagen materializa también la conciencia narrativa y los dos planos de la experiencia que configuran el relato (figura 19). El protagonista de la historia elabora una forma de subjetividad que normaliza lo fantástico y lo subsume en la realidad natural, por ello la disociación visual que presenta la figura del muchacho respecto a su sombra ofrece una lectura simbólica de su dualidad interior y del conflicto entre estos dos mundos contrapuestos.

\section{CONCLusión}

Bajo el paraguas de la intermedialidad y en los márgenes de dos subcategorías mediales - la combinación y la transposición- hemos visto cómo la simbiosis semiológica de microrrelato e imagen configura un núcleo de sentido en cinco títulos de la literatura no mimética.

Si los Cuentos malvados, paradigma de la reinvención de un libro como objeto cultural complejo, revelan la potencialidad de las imágenes para establecer marcos cognitivos, los Cuentos del libro de la noche ensalzan el poder de las ilustraciones para visualizar y completar la dimensión abstracta de la palabra. Y como sugiere el prologuista ficcional de las Formulaciones tautológicas al glosar el poder de la metáfora, también los relatos de este libro, que normalizan con el 
absurdo el surrealismo de los collages, se erigen en metáforas de la narratividad implícita en una imagen. Pero es en Casa de muñecas donde el potencial creativo de las ilustraciones se muestra como una fuerza capaz de construir una estructura y representar una estética, en este caso la de lo gótico y lo ominoso. Finalmente, Ajuar literario. El cómic nos recuerda que la esencialidad y la estructura del microrrelato son extrapolables a la narrativa gráfica, donde la calidad denotativa de sus dibujos potencia todavía más, si cabe, el horror.

Cierto es que, con la excepción de Formulaciones tautológicas, la creación del microrrelato precede en el tiempo a las ilustraciones que lo acompañan, pero la conclusión más rotunda es que en el producto final se borran las jerarquías entre ambos sistemas semióticos y que juntos conforman una unidad significativa que enriquece la experiencia literaria e intelectual al tiempo que corporizan lo ominoso, lo fantástico, lo irracional.

BibLIOGRAFíA

Agosto, Denise (1999): «One and inseparable: interdependent storytelling in picture storybooks», Children's Literature in Education, núm. 30, pp. 267-280.

Abello Verano, Ana (2019): «Cartografías de lo sobrenatural: Imaginería de terror gótico en la narrativa breve de Patricia Esteban Erlés», Dicenda. Estudios de lengua y literatura españolas, núm. 37, pp. 31-49.

Álvarez Méndez, Natalia (2019): «Domestic Horror and Gender: Conflicts in the Narratives of Patricia Esteban Erlés», Bulletin of Hispanic Studies, núm. 96, pp. 627-640.

ANDRES-SUÁREZ, Irene (2007): «El microrrelato: caracterización y limitación del género», en Teresa Gómez Trueba (ed.), Mundos mínimos. El microrrelato en la literatura española contemporánea, Cátedra Miguel Delibes/Llibros del Pexe, Valladolid-Gijón, pp. 11-39.

- (2010): El microrrelato español. Una estética de la elipsis, Menoscuarto, Palencia.

BARDin, Laurence (1975): «Le texte et l'image», Communication et langages, núm. 26, pp. 98-112.

BARTHES, Roland (1964): «Rhétorique de l'image», Communications, núm. 8, pp. 40-51.

Benítez Reyes, Felipe (2010): Formulaciones tautológicas (Informes y collages), Zut, Málaga.

BENNET, Michael Y. (2015): The Cambridge Introduction to Theatre and Literature of the Absurd, Cambridge University Press, Cambridge.

Calvo Revilla, Ana (2019): «Lo siniestro y la subversión de lo fantástico en Casa de muñecas», en María Martínez Deyros y Carmen Morán Rodríguez (eds.), Pasado, presente y futuro del microrrelato hispánico, Peter Lang, Berlín, pp. 113-132.

Chatman, Seymour (1978): Story and Discourse: Narrative Structure in Fiction and Film, Cornell University Press, Ithaca. 
CoHn, Neil (2013): «Beyond speech balloons ad thought bubbles: the integration of text and image», Semiotica, núm. 197, pp. 35-63.

De la Varga, Raquel (2015): «Mujeres que matan: dimensiones del monstruo en Patricia Esteban Erlés», en Natalia Álvarez Méndez y Ana Abello Verano (eds.), Espejismos de la realidad. Percepciones de lo insólito en la literatura española (siglos XIXXxI), Universidad de León, León, pp. 233-242.

Díez Cово, Rosa María (2019): «Ecos góticos en el microrrelato contemporáneo español: una travesía en/tre orillas atlánticas», Microtextualidades. Revista Internacional de Microrrelato y Microficción, núm. 5, pp. 45-66.

Elleström, Lars (2019): Transmedial Narration. Narratives and Stories in Different Media, Palgrave Macmillan, Hampshire.

EnCINAR, Ángeles (2011): «La visualización de las ficciones. Cuentos del libro de la noche de José María Merino», en Geneviève Champeau (ed.), Nuevos derroteros de la narrativa española actual. Veinte años de creación, Prensas Universitarias, Zaragoza, pp. 201-215.

Esteban Erlés, Patricia (2012): Casa de muñecas, Páginas de Espuma, Madrid.

Freire, Espido (2010): Cuentos malvados [2003], Páginas de Espuma, Madrid.

GABBARD, Tyler (2017): "Cognitive approach to sinister, very short fiction in Casa de muñecas», Spanish and Portuguese Review, núm. 3, pp. 87-98.

GenetTe, Gérard (1987): Seuils, Éditions du Seuil, París.

Humphreys, Karen (2006): «Collages communicants: Visual representation in the collage-albums of Max Ernst and Valentine Penrose», Contemporary French and Francophone Studies, vol. 10, núm. 4, pp. 377-387.

HutcheOn, Linda, y Siobhan O'FlynN (2006): A Theory of Adaptation, Routledge, Londres/Nueva York.

IwASAKI, Fernando (2015): Ajuar funerario [2004], Páginas de Espuma, Madrid.

IwASAKI, Fernando, Beñat Olea e Imanol Ortiz (2018): Ajuar funerario, Páginas de Espuma, Madrid.

JACKSON, Rosemary, (2003): Fantasy. The Literature of Subversion [1981], Routledge, Londres/Nueva York.

JimÉnEz TAPIA, Gonzalo (2018): «Entrevista a Patricia Esteban Erlés», Microtextualidades. Revista Internacional de microrrelato y minificción, núm. 3, pp. 212-216.

JunG, Carl G., (2004): The Undiscovered Self [1957], Routledge, Londres/Nueva York.

KAYSER, Wolfgang (2010): Lo grotesco. Su realización en literatura y pintura [1957], Antonio Machado Libros, Madrid.

KRESS, Gunther, y Theo van LeEUwEN (1996): Reading Images: The Grammar of Visual Design, Routledge, Londres.

Merino, José María (2004): Ficción continua, Seix Barral, Barcelona.

- (2005): Cuentos del libro de la noche, Alfaguara, Madrid.

Noguerol, Francisca (2008): «Minificción e imagen: cuando la descripción gana la partida», en Irene Andres-Suárez y Antonio Rivas (eds.), La era de la brevedad: el microrrelato hispánico, Menoscuarto, Palencia, pp. 183-206.

- (2009): «El escalofrío en la última minificción hispánica: Ajuar funerario, de Fernando Iwasaki», en Jesús Montoya y Ángel Esteban (eds.), Miradas oblicuas en la 
narrativa latinoamericana contemporánea: límites de lo real, fronteras de lo fantástico, Iberoamericana, Madrid, pp. 195-217.

Parramon, Pere (2020): Arte fantástico: estrategias visuales de lo imposible, Tesis doctoral, Universitat de Girona. Disponible en <http:/ / hdl.handle.net/10803/671539> [11-12-2021].

Pérez-Bustamante, Ana Sofía (2014): «La propiedad del paraíso y otros collages de Felipe Benítez Reyes», en José Jurado Morales (ed.), Felipe Benitez Reyes, la literatura como caleidoscopio, Visor Libros, Madrid, pp. 333-369.

Pina Arrabal, Álvaro (2020): «El tránsito de la literatura al cómic: Ajuar Funerario, de Fernando Iwasaki», Pasavento. Revista de Estudios Hispánicos, vol. VIII, núm. 1, pp. 209-236.

RAJEWSKY, Irina O. (2005): «Intermediality, Intertextuality, and Remediation: A Literary Perspective on Intermediality», Intermédialités / Intermediality, núm. 6, pp. 43-64.

RoAs, David (2011): Tras los límites de lo real. Una definición de lo fantástico, Páginas de Espuma, Madrid.

Ródenas De Moya, Domingo (2007): «Consideraciones sobre la estética de lo mínimo», en Teresa Gómez Trueba (ed.), Mundos mínimos. El microrrelato en la literatura española contemporánea, Cátedra Miguel Delibes/Llibros del Pexe, Valladolid-Gijón, pp. 67-93.

Rodiek, Christoph (2012): «Microrrelato e imagen. El caso de José María Merino», Siglo XXI. Literatura y cultura españolas, vol. 9-10, pp. 189-202.

RodrígueZ, Samuel (2020): «Monstruos (metafísicos) en Cuentos malvados de Espido Freire», Microtextualidades. Revista Internacional de Microrrelato y Microficción, núm. 8, pp. 49-69.

SÁncheZ VilladAngos, Nuria (2015): «Lo fantástico frente a lo real y lo grotesco en los cuentos de Patricia Esteban Erlés», Tropelías. Revista de Teoría de la Literatura y Literatura Comparada, núm. 23, pp. 473-486.

StewArt, Susan (1993): On Longing: Narratives of the Miniature, the Gigantic, the Souvenir, the Collection [1984], Penguin Books, Durham-Londres.

Tusquets, Esther (2012): Confesiones de una editora poco mentirosa [2005], Ediciones B, Barcelona.

Velázquez Velázquez, Raquel (2012): «Procedimientos de irrupción de lo fantástico en Ajuar funerario, de Fernando Iwasaki», Cartaphilus. Revista de Investigación y Crítica Estética, núm.10, pp. 178-194.

- (2019): «Quaerens quem devoret: El resurgimiento de la mujer mantis o mujer devoradora en el microrrelato fantástico español del siglo XXI», Bulletin of Hispanic Studies, núm. 96, pp. 627-640. 